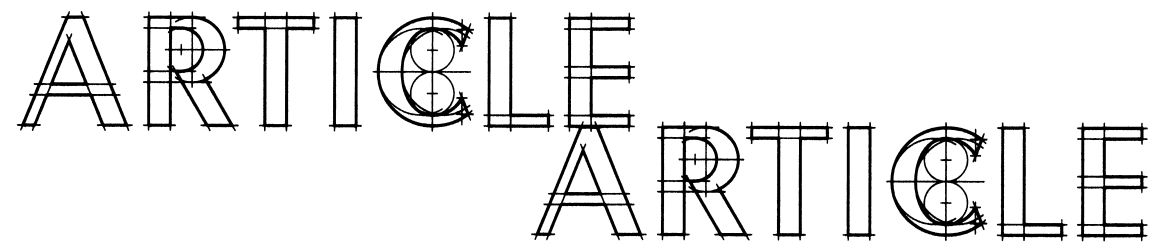

\title{
2007 Report to the Optometric Leaders Forum from the Vision Institute of Canada
}

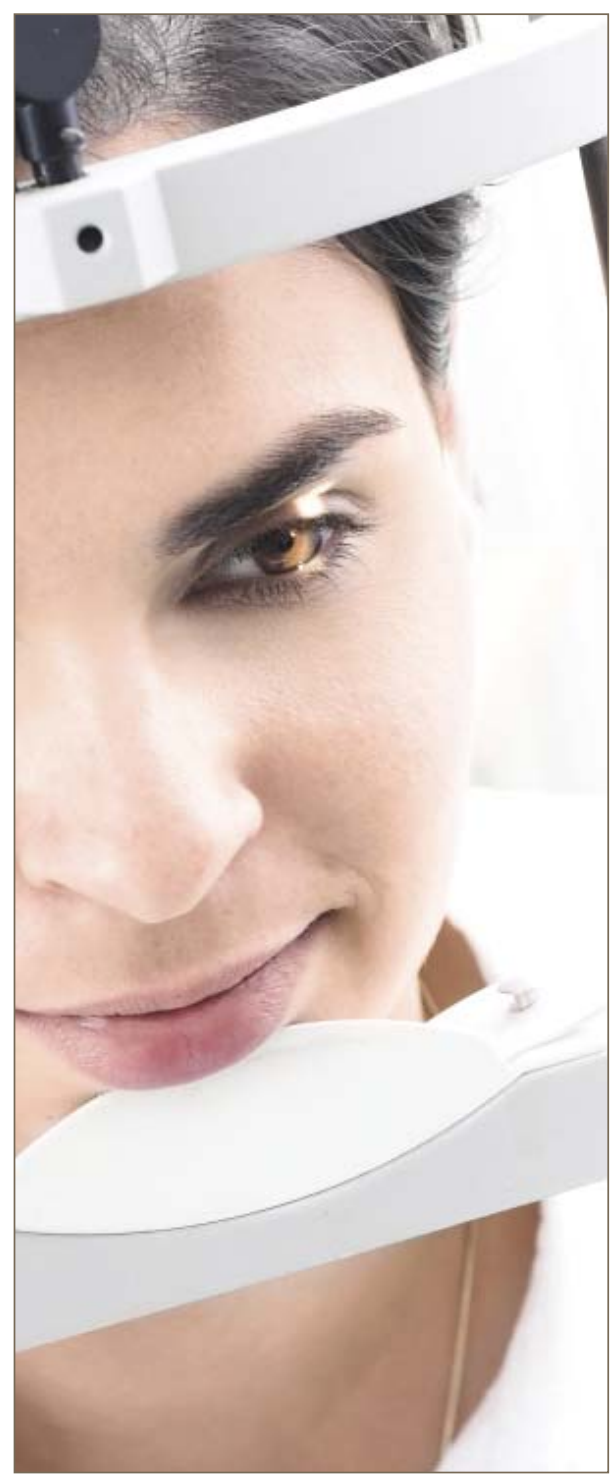

The Vision Institute of Canada was originally established in 1981 as an optometric resource centre for the profession where practitioners could refer difficult cases for second opinions, for access to specialized instruments and equipment which were not the standard of care in most offices at the time, to be an educational resource for the profession, and to provide charitable vision care services to members of the public with financial or other special needs.

The Institute was started with the financial assistance of the College of Optometrists of Ontario, the Ontario Association of Optometrists, and the School of Optometry in Waterloo. It is a multi-disciplinary clinic with four fully functioning exam rooms, a low vision centre, library and dispensary. It has a combined full and part-time staff of eight people and accommodates over 4000 patient visits a year. Its main clinical focus is pediatrics, low vision, and specialized contact lens care. The Institute also provides a student internship program to as many as twelve final year optometry students every year. These students stay for three months each and under the clinical supervision of Institute staff, are exposed to very challenging patients and cases.

The Institute also provides vision care services to over 20 nursing homes and chronic care facilities in the Greater Toronto Area.

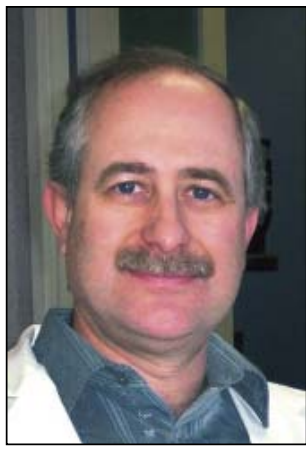

Dr. Paul Chris, OD Executive Director Vision Institute of Canada

16 York Mills Road, Suite 110

Toronto, Ontario M2P 2E5

apchris@look.ca www.visioninstitute. optometry.net 


\section{ARTICLE ARTICLE}

These programs are for the most part charitable since the remuneration from OHIP or from the dispensing of ophthalmic appliances does not cover the true cost of providing this service. We also continue to operate a program providing free comprehensive eye examinations at the clinic to the many women and children living in family shelters in the Greater Toronto Area in association with shelters that are run by the YWCA. This program exposes and sensitizes our clinical interns to the issue of domestic abuse. It is also an opportunity for the Institute to get more involved in community and social action around a very vulnerable segment of our society that has become more at risk since the deinsuring of eye exams for persons aged 20 to 64. We also receive and accept numerous referrals of clients from various social service agencies who are in need of vision care services but cannot afford them.

The year 2007 has been a very successful year for the Institute. Our donation program and corporate sponsorship, together with revenues from our continuing education programs and conferences allowed the Vision Institute to again successfully balance its budget for the year. We are also grateful to the Canadian Optometric Education Trust Fund for its second year of funding our program of Vision Services for Family Shelter Residents.

In 2007 the Board of Directors of the Institute approved a research project to look at the delivery of Optometric Vision Care Services to Aboriginal Communities in Canada. The purpose of this project over

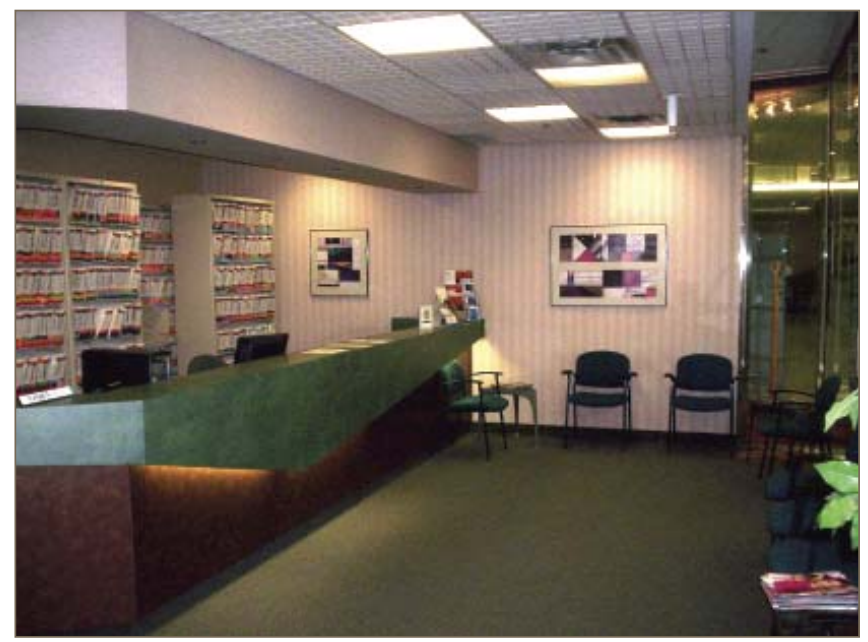

the next two years will be to determine the level of optometric vision care services being provided to our native communities and establish a basis for out-reach programs to those communities that are in the greatest need of care. There have been no studies done, to the best of our knowledge, on the level of optometric care or the amount of uncorrected refractive error in our aboriginal populations on reserve. We will host an Aboriginal Vision Health Conference in Ottawa in May, 2010, to present the results of this study with an overview of issues related to vision and eye health in Canadian aboriginal communities. Dr. Barbara Robinson, $\mathrm{OD}, \mathrm{MPH}, \mathrm{PhD}$, from the University of Waterloo has partnered with us in the development this program. The support of our Canadian and provincial associations would be very welcomed.

The Vision Institute hosted two very successful continuing education conferences in 2007. In May, we held a 10-hour Anterior Segment Disease and Treatment Course which included a two hour Glaucoma Management Course presented by Dr. Paul Karpecki. This was hosted for our Northern Ontario colleagues, in Sudbury, Ontario, on May 12th and 13th, 2007 at the Radisson Hotel and Conference Centre. It was followed by a two-hour hands-on workshop featuring Heidelberg Retina Tomography in the assessment of glaucoma.

On November 2nd, 3rd, and 4th, 2007, the Institute hosted a 20 Hour TPA Refresher Course with Dr. Ron Melton and Dr. Randall Thomas who brought their 20-hour Current Therapy in Ocular Disease Course

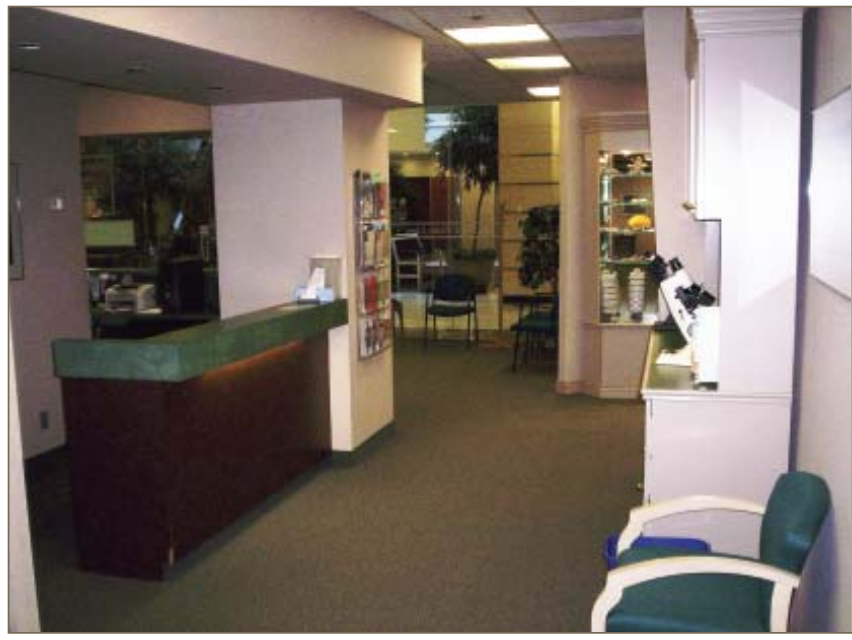

C A N A D I A N J O U R N A L O F O P T O METR

R E V U E C A N A D I E N N E D ' O P T O M É T R I E
Vol 70 No 2

March / mars 2008 
to the Hilton Suites Hotel and Conference Centre in Markham, Ontario. This was held in affiliation with the Pennsylvania College of Optometry and met the educational requirements of the College of Optometrists of Ontario as a 20 hour TPA Refresher Course for members to prescribe drugs. The program was sold-out with 458 practitioners in attendance. The Trade Show was very well attended and featured over 30 suppliers from the vision care industry.

In 2007, the Vision Institute made a stakeholder submission to the College of Opticians of Ontario in response to their Proposed Standard of Practice for Optician Performed Refraction. We were concerned that their proposed standard did not include the important provision that refraction by opticians only be performed under the direct in-office supervision of the prescribing doctor. This requirement for direct supervision is the position of the College of Optometrists and the College of Physicians and Surgeons of Ontario. The optician's proposed standard would put the public at a risk of harm. The Institute's submission can be viewed on our web-site.

In 2008, the Institute will be hosting two national conferences. Several very prominent experts in the field of nutrition and vision have accepted an invitation to speak at a symposium, to be held in Calgary, Alberta on May 31st and June 1st, 2008. This two-day continuing education program will be directed towards optometrists, dietitians, physicians, and other healthcare professionals interested in nutrition and vision.

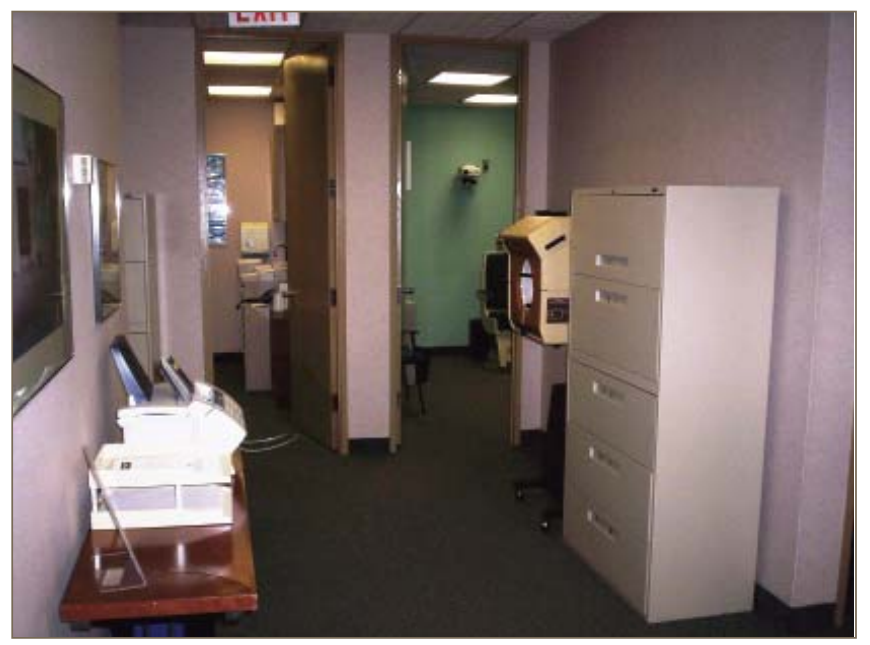

It will cover topics such as diabetic and hypertensive retinopathy, macular degeneration, juvenile-onset myopia, and other nutrition-related diseases with a focus on vision and eye health. Speakers include Dr. Steven Pratt, MD, an ophthalmologist and world-renowned authority on the role of nutrition and lifestyle in the prevention of disease, and author of the best sellingbook SuperFoods Rx; Dr. Loren Cordain, PhD, a leading expert on the diet of paleolithic cultures and author of The Paleo Diet and The Paleo Diet for Athletes; and Dr. Stuart Richer, OD, PhD, principal investigator of the Veterans Lutein Antioxidant Supplementation Trial (LAST) on lutein and macular degeneration. There will be a Nutraceutical Trade Show, Book Fair, and an Ocular Imaging Workshop. Dr. Cordain will present the keynote lecture: Origins and Evolution of the Western Diet: Health Implications for the 21st Century based on his February 2005 paper in the American Journal of Clinical Nutrition.

This Nutrition and Vision symposium will come to Toronto on November 7th, 8th, and 9th, 2008 as part of our 20 Hour CE Annual Fall Conference and Trade Show. We will also feature Dr. Louis J. Catania, OD, presenting a variety of lecture topics related to therapeutic pharmaceutical agents in optometric practice. This three-day program will be held at the Hilton Suites Hotel and Conference Centre in Markham, Ontario.

The Vision Institute will have completed by November 2008, a patient-education pamphlet on Nutrition and Vision for optometrists to give to their patients.

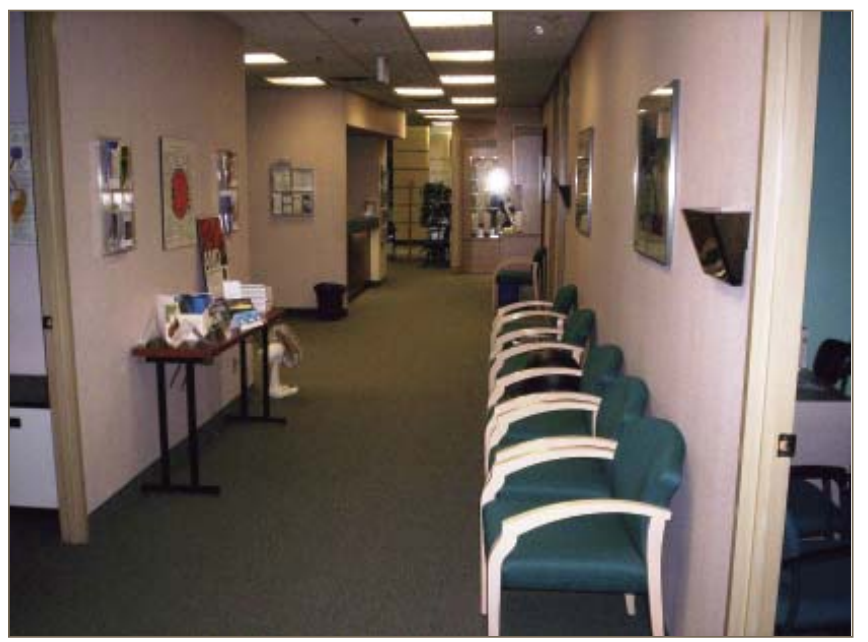

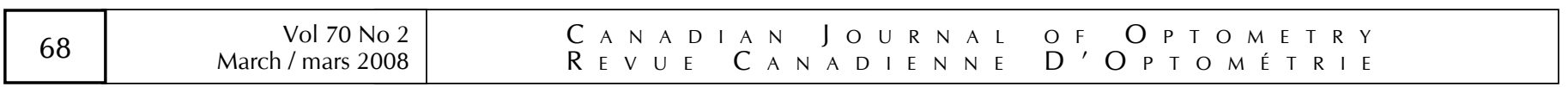

